\title{
Perceptions of Self Sampling and Urine Sampling Versus Traditional Pap Smear in Rural Settings of Cuenca Ecuador
}

\author{
Universidad de Cuenca \\ Vivian Alejandra Neira \\ Universidad de Cuenca \\ José Ortíz \\ Universidad de Cuenca \\ Ruth Maldonado - Rengel \\ Universidad Técnica Particular de Loja \\ Diana López \\ University of Azuay

\section{Gabriela Guerra} \\ Universidad de Cuenca \\ María Paz Orellana \\ Universidad de Cuenca \\ Ina Benoy \\ AMBIOR, University of Antwerp \\ Tesifón Parrón Carreño \\ University of Almería \\ Veronique Verhoeven \\ University of Antwerp
}

Bernardo Vega ( $\square$ bernardo.vegac@ucuenca.edu.ec )

\section{Research Article}

Keywords: Cervical cancer, self sampling, acceptance, barriers and facilitators

Posted Date: October 15th, 2021

DOI: https://doi.org/10.21203/rs.3.rs-944198/v1

License: @) (i) This work is licensed under a Creative Commons Attribution 4.0 International License. Read Full License 


\section{Abstract}

Background: Cervical cancer screening has demonstrated high effectiveness reducing cervical cancer mortality worldwide, however there is still a high rate of under screened women. Pap smear technique is often considered an uncomfortable examination technique that can reduce uptake of the examination. This study explores the perceptions of self sampling and urine sampling versus traditional pap smear in rural settings of Cuenca Ecuador.

Methods A qualitative study with a phenomenological approach was performed. Focus groups were conducted in El Valle parish of Azuay province of Cuenca Ecuador. Women natives of this rural area were included in this research.

Results A total of 45 women, have participated in 7 focus groups, all participants live in rural area. Pap smear technique is considered a painful, intrusive and embarrassing method, however participants believe that is more reliable, compared with self sampling methods, due a direct visualization of the cervix and because other problems could be detected during the examination. Advantages of self-sampling include that it is perceived as comfortable, less painful, participation rate, timesaving, because it can be done at home, and can be made widely available for example through pharmacies or with help of traditional healers. Barriers are related with doubts of the quality of the sample and lack of capability to perform it.

Conclusions This study shows that women consider self sampling methods as a possible solution to overcome barriers that could reduce the uptake of cervical cancer screening; privacy, comfortability and accessibility are major advantages of those methods. Self examination at home reduces waiting times in health centers, with high demand of attention or during Covid pandemic. Barriers are mainly related with doubts in the self proficiency to perform the test and the accuracy of the results. Those doubts are understandable, because self sampling methods are never used before in Ecuador, and could be solved with an adequate training and information for the patients. Further studies that measure acceptability and sensitivity in real application are required to address the utility of self sampling methods in a rural context.

\section{Background}

Since 1970 cervical cancer mortality has experienced a decrease of $70 \%$ in developed countries due to the implementation of large population screening, vaccination against human papilloma virus (HPV) and an accurate follow up and treatment of premalignant lesions (1). Around, $80 \%$ of cervical cancer deaths occurred in Low and Middle Income Countries (LMIC) (2); the disparities in cervical cancer prevention policies and the low coverage of screening could explain higher rates in those settings (3) (4) .

Lack of access and adherence to routine cervical cancer screening could reduce the possibilities to detect cervical cancer lesions in early stages (5) (6). Perceived barriers for successful implementation of screening are the quality of services, associated with long waiting times for the appointment and the results, lack of privacy (7) and individual factors like anxiety caused by the examination, discomfort, fear and shame (8) (9). In addition, lack of risk perception and knowledge about cervical cancer could be obstacles in women from ethnic minorities or those who live in rural areas (10) (11).

In Ecuador, cervical cancer (CC) is the second leading cause of cancer in women of all ages. During 2020, 1534 new cases were detected and 813 women died by this cause (12) The number of deaths and new cases have not shown a clear reduction in the last 10 years in the country (13) (14).

Thus, Ecuador installed a national strategy for integral attention on cancer focused on cervical cancer screening and vaccination (15) (16) (17). The public health system grants free access to screening mainly based on cytology (18) .The 58,4\% of all women in their reproductive age have had almost one cervical screening episode during their lifetime; in other words $41,6 \%$ of women in Ecuador are never screened (19).

Innovative strategies in the communities based on primary HPV (Human Papilloma Virus) screening have demonstrated more effectiveness than pap smear in the detection of high grade lesions (20) (21) (22). Among those strategies, self-sampling methods as a primary method of screening have shown an increase of adherence among underscreened women (23)(24). 
Urine sampling and vaginal sampling have demonstrated an acceptable sensitivity and specificity in the diagnosis of HPV compared with traditional cervical sampling (25) (26) (27).

Self sampling has shown good acceptance in indigenous populations and in rural areas, increasing the adherence to cervical cancer screening (28) (29). It could be a cost- effective strategy that could overcome barriers in settings with low coverage and acceptance of cervical screening (26) (30) (31).

In Ecuador no strategies based on self sampling or urine sampling for HPV detection have been applied in community settings so far. Women in urban and rural areas have never been exposed to this kind of sampling; that is why the aim of this study is to identify the perceptions of self sampling and urine sampling versus traditional pap smear in rural settings of Cuenca Ecuador. This study precedes the implementation of a pilot self sampling project (CAMIE project).

\section{Methodology}

\section{Research design}

This qualitative study was conducted from January of March 2021 in Ecuador (Cuenca) in the rural community of the El Valle parish as part of the qualitative package of CAMIE project (Making cervix cancer screening accessible through self sampling: a step towards health equality by empowering women in an intercultural context). Therefore, Focus Group of Discussion (FGD), was selected as a method to allow participants to interact and share their ideas. The phenomenological paradigm was the guide to understand the different perceptions of the community. Reporting was done based on the SRQR guidelines for qualitative research papers.

\section{Ethical approval}

This study was approved under guidance of the Declaration of Helsinki and the Council for International Organizations of Medical Sciences (CIOMS). All procedures involving human participants were approved by the Bioethical Committee of the University of Cuenca, approval code: UC-COBIAS-2020-263. Before the starting of each FGD, an informed consent was signed by each participant who was free to decline participation or withdraw at any time

\section{Recruitment and setting}

A convenience sampling recruitment was applied; women in the parish were recruited by means of a snowball technique along with the help of the two primary health centers of the community and the local government of the parish.

Being older than 18 years, having sexual onset, have at least one pap smear done by a physician and living in the area where the primary requisites to be considered eligible for the FGD. Face to face FGD took place in community settings and in places provided by health centers. All the FGD were conducted by the principal investigator and one researcher of the project. Table number 2 provides a general overview of participants. The number of focus groups was defined by the saturation of the discussion in FGD.

\section{Data collection}

For data collection a semi-structured guide was developed, the Theoretical Framework of Acceptability (32) was used to construct the interview guides. The guide has questions to address the following objectives: a.- knowledge and perceptions about cervical cancer, b.- knowledge about cervical cancer screening, c.- to understand perception and acceptability about self sampling. 
Table $\mathrm{N}^{\circ} 1$ shows the questions of the interview guide. Since self-sampling methods have never been used in Ecuador, the selfsampling device (Evalyn ${ }^{\circledR}$ Brush from Rovers Medical Devices) was given to the participants and additional explanation of the application was provided.

\section{Table $N^{\circ} 1$ Focus group interview guide}

Knowledge about cervical Cancer

- What do you know about this illness

- Which are the causes of this illness

- How is it transmitted

Knowledge about cervical cancer screening

- Indications for the screening (when should the screening start?; which conditions are optimal for the screening?)

- Follow up and frequency of screening (How often should the screening be done?; what to do if there is an abnormal result?)

- Which factors increase adherence to the screening?

- Which factors decrease adherence to the screening?

Sampling methods for diagnosis

- Pap smear (Which are the advantages and barriers of this method?)

- Self-sampling (Which are the advantages and barriers of this method?)

- Urine sampling (Which are the advantages and barriers of this method?)

This report focuses on the categories related to the last question, in order to understand perceived barriers as well advantages of sampling methods, before we started our self sampling field study. All interviews were recorded, transcripted and uploaded to Nvivo 12.

\section{Data analysis.}

Theoretical framework of acceptability was used to define categories. Advantages and barriers of each method were defined as a priori categories; emerging categories were identified by inductive analysis of each narrative related with the key codes. Emerging categories were classified as positive perceptions and barriers.

The coding and the analysis were conducted by the first author and discussed with the coauthors members of CAMIE project. The final result reflects an agreement of all researchers involved.

\section{Results}

A total of 7 focus groups were held between January 2020 and March 2021; 45 women that live in this rural area were selected to participate. General characteristics of the participants are presented in table $\mathrm{N}^{\circ} 2$.

\section{Table $\mathbf{N}^{\circ} 2$ Socio demographic description.}




\begin{tabular}{|c|c|}
\hline Age & $N(\%)$ \\
\hline 25 to 29 & $4(8,9)$ \\
\hline 30 to 39 & $14(31,1)$ \\
\hline 40 to 49 & $12(26,7)$ \\
\hline 50 to 59 & $10(22,2)$ \\
\hline 60 and more & $5(11,1)$ \\
\hline \multicolumn{2}{|l|}{ Education } \\
\hline Primary & $16(35,6)$ \\
\hline High School & $12(26,7)$ \\
\hline Higher & $17(37,8)$ \\
\hline \multicolumn{2}{|l|}{ Civil Status } \\
\hline Married & $29(64,4)$ \\
\hline Divorced & $3(6,7)$ \\
\hline Single & $7(15,6)$ \\
\hline Stable Union & $3(6,7)$ \\
\hline Widow & $3(6,7)$ \\
\hline \multicolumn{2}{|l|}{ Main activity } \\
\hline House wife & $14(31,1)$ \\
\hline Saleswoman & $1(2,2)$ \\
\hline Seamstress & $1(2,2)$ \\
\hline Employed & $6(13,3)$ \\
\hline Agriculture & $8(17,8)$ \\
\hline None & $2(4,4)$ \\
\hline Other & $13(28,9)$ \\
\hline \multicolumn{2}{|c|}{ Age of sexual onset } \\
\hline 14 and less & $2(4,4)$ \\
\hline 15 to 19 & $18(40,0)$ \\
\hline 20 to 24 & $20(44,4)$ \\
\hline 25 to 29 & $4(8,9)$ \\
\hline 30 and more & $1(2,2)$ \\
\hline
\end{tabular}

\section{Pap smear.}

Advantages. 
All women considered Pap smear (clinician sampling) as the gold standard for prevention and detection of cervical cancer; therefore, women think that it is more effective, precise and secure for the diagnosis (Q1). They think that a direct inspection of the vagina grants health professionals a direct view and can directly reach the cervix and that is an advantage to self-sampling (Q2). In addition, some women think that during the examination of pap smears other infections could be detected and treated at the same time (Q3).

Q 1 "Because it seems to me that it is safer". (Participant 43 years FDG 7).

Q2 "Confidence that goes where it has to go". (Participant 35 years FDG 1).

Q3"That is why I do a Pap smear in that sense, because there are infections too, that is why I also do a Pap smear to receive other kinds of treatment for infections". (Participant 45years FDG 7).

Barriers.

Almost all women agreed that Pap smear is an uncomfortable examination, (Q4) most women feel pain, shame or discomfort during this examination (Q5). Some women feel they are mistreated during the examination and consider this type of examination as a breach on their intimate privacy (Q6)(Q7). All those feelings could be increased if the health professional is a male.

Q4 "A nightmare is how it is used to be. I tell you, years ago, I did not do the pap smear at all". (Participant 56 years FDG 5).

Q5 "Of course, discomfort, shame, annoyance practically. Yes it is a bit annoying". (Participant 38 years FDG 4).

Q6 "It's such a thing... how to say it? A violation!" Participant 58 years FDG 5)

Q7 "Take out (the clothes) and get naked, and sit back and spread your legs ... So that, all of that process is traumatic".

(Participant 35 years FDG 1)..

Q8 "But I think that shame is more, shame when a male gynecologist comes". Participant 38 years FDG 4).

Women believe that the speculum could hurt the genital tract and those injuries could cause infections and even cervical cancer (Q9) (Q10).

Q9 "That is very important to know because it is scary, because you know that it can hurt (the speculum) and when it already hurts (cervix), cancer hits there. That is what our elderly said, why would they go for it, if they get sicker (after the procedure)". (Participant 45 years FDG 7).

Q10 "I did the exam, after 3 days the breakout of pimples was coming down here and I was already going crazy, I had to hurry back to the health center to see why". (Participant 56 years FDG 5).

Most participants think that a pap smear is an invasive technique that takes a part of the cervix during the examination. In two focus groups, women think that the sound that is heard when the speculum opens, is caused by the fact that a piece of the cervix is taken out. (Q11).

Q11 "I speak for myself, for me it was something new and that bothered me like a, "troc"!(feel and hear a sound similar to "troc") It did something like that. I don't know if something is cute, pulled, I don't know what it was". (participant 40 years FDG 6).

Table $N^{\circ} 3$ summarizes the perceptions on pap smear as a screening tool.

Table $N^{\circ} 3$ perceived advantages and barriers of pap smear. 


\begin{tabular}{|ll|}
\hline Advantages & Barriers \\
\hline Considered as most reliable & Painful \\
Visualization of the cervix & Intrusive \\
Health care provider can detect other problems while taking pap smear & Inducing shame \\
& Worries about harmful effects \\
\hline
\end{tabular}

\section{Self-sampling (vaginal self-sampling)}

\section{Advantages.}

Women of all groups find positive aspects of self sampling, to them, it is a new and unknown method, but they are prone to test it and have the experience on their own (Q12). In addition women agreed that this method could reach under-screened women and save lives (Q13).

Q12 "It would be to do the test (I will take the test) and see if it is reliable" (Participant 30 years FGD 1).

Q13 "There would be more women (who can accede) and many deaths would be avoided because there are still, there are women who die from cancer of the uterus". (Participant 57 FGD 3).

Women in all focus groups consider that the waiting time to get an appointment and to get attention in the health centre will be reduced (Q14). Furthermore, they consider that self sampling may reduce or avoid absence to work (Q15).

Q14 "That it is no longer necessary to spend time in the health center, you can take the sample and only leave it there". (Participant 35 years FGD 5).

Q15 "Time, time is the worst enemy, how I already tell you, many (don't go) for work or due to other things ... and even if you have an appointment, it is not that you arrive and they attend to you, you have to be 20 minutes before, and if there was an emergency, you have bad luck! The emergency is given priority and you keep waiting for a turn". (Participant 40 years FGD 5).

All women agreed that self sampling could give more privacy; an additional advantage is that the test could be done at home when women have enough time (Q16). Women also believe that the procedure will be less painful (Q17).

Q16 "I can do it at home, by myself, I lock myself in the bathroom, rather than lie down in the room or in bed". (Participant 40 years FGD 5).

Q17 "If it is like this, I would have done it sooner, and so it could avoid the pain, when it is done (pap smear)". (Participant 40 years FGD 4).

An additional benefit is that during the covid-19 pandemic, self-sampling avoids to go to a health care center and that reduces the possibility to get infected (Q18).

Q"18 "With this virus, that you can catch it anywhere,(Covid 19) better to send it to the house and that's it, I think I can make myself direct". (Participant 58 years FGD 2).

Some women in the focus group practice ancestral medicine; they think that they could give some indications to other women in the community and offer them the device in order to engage women to cervical screening (Q19) In addition, another perceived advantage is that the device could be available in pharmacies and women could bring the sample to the laboratory (Q20). 
Q19 "Because we as ancestral medicine people, can talk and offer to our women, clients, communities" (Participant 52 years FGD 2).

Q20 "And if you can buy it in the pharmacy? .... you can take yourself... the sample, they give it to you and you can detect if there is a virus or disease. That it is something very practical and it will help and benefit a lot of women here in the parish". (Participant 38 years FGD 4).

\section{Barriers.}

Women have fear to be hurt by the device; during the application, in addition, they suppose they will feel pain (Q21) or shame during the sampling (Q22).

Q21 "I mean, there it is ugly inside that comes (comes out the brushes) and scratches what it has delicate! Inside Oh my God, he's been stiff! when I saw it first, I thought it was cotton". (Participant 58 years FGD 5).

Q22 "I say "I am ashamed." So that, it is more that if people should be trained; train, how they have to use". (Participant 64 years FGD 2).

All groups of women think that this is a good method, but they remark to have difficulties in the application of the technique of self-sampling; they think that an incorrect procedure could give inaccurate results, that is why some prefer to get a pap smear. They say that health personnel knows where to take the sample. (Q23) (Q24).

Q23 "One of the disadvantages, as I say, maybe when taking, not knowing or taking the sample for the first time, maybe as soon as something starts you can get hurt or you don't like it, or you take it wrong, if it doesn't go well. It was practically a waste". (Participant 40 years FGD 6).

Q24 "It would be much better for me. But now my question is if it would be okay? So I don't know how, what the method would be like... Because you suppose, the doctor knows how he takes it, where he takes it, what to take out, and I imagine it is more effective than one (self sampling)". (Participant 57 years FGD 3).

Some women consider self-sampling an incomplete examination, because when they go for a pap smear, health professionals can detect other pathologies like infections (Q25).

Q25 "Because I would not only like to know if I have the papilloma virus, but also anything that may be happening inside, and the doctor, apart from taking the sample, will see if there are injuries. So I do prefer to go to the doctor". (Participant 35 years FGD 5)

On table $\mathrm{N}^{\circ} 4$ a summary of perceptions of self-sampling is shown.

Table $\mathbf{N}^{\circ} 4$ perceived advantages and barriers of self sampling.

\begin{tabular}{|ll}
\hline Advantages & Barriers \\
More comfortable, less painful & $\begin{array}{l}\text { Fear to do something wrong, to hurt } \\
\text { themselves }\end{array}$ \\
$\begin{array}{l}\text { Could increase participation rate } \\
\text { Time saving; can be done at home }\end{array}$ & $\begin{array}{l}\text { Fear that a self-taken sample is not of } \\
\text { good quality }\end{array}$ \\
$\begin{array}{l}\text { No need to go somewhere } \\
\begin{array}{l}\text { Can be made widely available for example through pharmacies or with help of } \\
\text { medicos ancestrales }\end{array}\end{array}$ \\
\hline
\end{tabular}




\section{Urine sampling.}

Advantages.

This technique presents more doubts in effectiveness, compared with pap smear and self sampling, among women but they consider it the most acceptable and user-friendly (Q26). It grants more privacy, turning it more comfortable and acceptable. Almost all women have gotten a urine sample at least once in their lifetime so they could compare easily with pap smear (Q28).

Q26 "Time too. With the urine test it would also be much more comfortable, easier". (Participant 35 years FGD 1).

Q27 "If with this, cancer is detected in the uterus, that is, I prefer urine because I go to the bathroom, do urine... .. More relaxed". (Participant 43 years FGD 6).

Q28 "In other words, we have already done the urine ... so we used to do it". (Participant 43 years FGD 6).

One great advantage perceived by all women is that urine sampling avoids the introduction of devices in the vagina. They believe that it is comfortable, reduces shame and increases privacy (Q29). Women consider that this method could engage women that are underscreened due the facility and acceptance of the method (Q30).

Q29 "Sure, urine would be more feasible for me. In the urine I have no longer to be showing, nothing is it going to be introduced". (Participant 58 years FGD 2).

Q30 "And even an easier way and therefore if all the people will came ... I swear that all the women will uptake it". (Participant 57 years $F G D 3$ ).

\section{$\underline{\text { Barriers }}$}

Almost all patients have doubts about the effectiveness of the method (Q31). Incorrect technique of urine sampling collection and contamination could lead to non-accurate results (Q32); some women believe that urine sample should be taken in the same circumstances as a pap smear. Normally, this is controlled by the health personnel prior to the examination and without this control, urine sampling could give erroneous results (Q33).

Q31 "But if, for example, if in the cervix there were something ... they detected me, I don't remember what the name was like, like some pimples ... they wouldn't see that, therefore (prefer) the traditional one.... No, no, the one from urine, that would not detect". (Participant 51 years FGD 1).

Q32 "Well, you also run a risk of contamination no? ... well, I don't know, I personally believe that at some point we can mishandle or contaminate the sample in one way or another". (Participant 59 years FGD 7).

Q33 "They always give recommendations to get a pap smear, do not have intercourse ... 72 hours in advance. (Urine) That is not safe, (and needs) hygiene care”. (Participant 30 years FGD 1).

Questions emerge on the storage and transportation of the samples, and there are concerns about possible spilling of the sample (Q34).

Q34 "Be careful to bring urine, all of that would also be a bit of a disadvantage, because you take this (self-intake device), put it there, cover it and... maybe it (the sample) will be spreading, it will happen. On the other hand, in urine you do have to be very careful when bringin..., I think". (Participant 40 years FDG 6).

Table $\mathrm{N}^{\circ} 5$ summarizes the perceptions about urine sampling.

Table $\mathbf{N}^{\bullet} 5$ perceived advantages and barriers of urine sampling. 


\begin{tabular}{|ll|}
\hline Advantages & Barriers \\
\hline Most user friendly and easy & Fear that urine is not reliable \\
No need to insert devices & Fear that a self-taken sample is not of good quality \\
Familiar for most women & Worries about logistic chain \\
\hline
\end{tabular}

\section{Discussion}

The aim of this study was to determine the acceptance of vaginal self-sampling and urine sampling among women that live in rural settings of Cuenca, Ecuador.

This study found that the participants in FGD consider that self-sampling methods (vaginal self sampling and urine sampling) can be a good and acceptable alternative to pap smear. However, they tend to be wary as well, about the accuracy and reliability of self-sampling test, compared to pap smear. Additionally, they expressed preoccupation about the capability to do the self sampling by themselves, and to get injured during the process. Participants also found some advantages and barriers in each method that could increase or decrease the acceptance.

Participants in FGD consider that the routine technique for cytology is an uncomfortable and even painful procedure. In addition, the process of the examination increases the feeling of embarrassment and lack of privacy; they believe that these barriers compromise participation rates. Similar results were presented in the literature; YEO Mun in Singapure and Grigore M in Rumania, found that the discomfort that women experience during a gynecological examination with speculum, could reduce the uptake of cervical cancer among women (33) (34).

Furthermore, some women in our study consider this procedure harmful and could cause illnesses after the examination, such as infection of the genital tract or even cancer.

Sometimes they think that they are healthy prior to examination and when abnormal results of the pap smear come, they get confused pointing the examination as the cause of the illness. Similar results were found in research conducted by Kabalika et al, in Zambia (35). Lack of knowledge about cervical cancer mixed with cultural believes could explain this situation. (34)

Nevertheless, women in our study considered traditional sample collection and cytology with speculum as the gold standard for cervical cancer screening and diagnosis. Some of them prefer this examination instead of self-sampling. This situation could be explained because in Ecuador gynecological examination with speculum is the standard technique for cervical sampling (15). In addition, pap smear has a long history of implementation in different settings as the only primary-cancer screening method. Furthermore, since HPV testing is currently performed on pap smears as well, women are not aware of differences between cytological and primary HPV screening (26) (36) (37) (38).

Another argument for why they prefer the traditional sampling with speculum rather than the self-sampling method is the lack of knowledge about the latest's efficacy, accuracy, and advantages. However, evidence shows that when a self-sampling method is offered at community level, a high level of acceptance is obtained (23).

Related to self-sampling methods (urine and vaginal self-sampling) in this research, almost all participants perceive selfsampling methods, as more comfortable, less painful and useful to overcome barriers of routine screening for cancer prevention. Similar results were found by Shin et al. in Korea: women that undergo through HPV self-sampling have a higher acceptance compared to pap smear traditional method (urine sampling OR 2,47; self-sampling OR 2,01) (39). Women consider that self-sampling methods (Urine sampling and vaginal self-sampling) are related with more privacy, less embarrassment, less painful and easy to use (40). 
An additional advantage according to our participants is that self-sampling methods could be provided by midwives, community workers and community ancestral medicine healers that could serve as link between the community and the health centers. This kind of initiative has demonstrated effectiveness in rural communities to engage underserved women. (41) (26)

Despite the good perceptions of self-sampling methods, women in our research have doubts about their capacity to perform the technique correctly; the same situation was found by Sy et al. in Micronesia, where women prefer to have a trained worker instead of themselves taking the sample (42). In a study in Thailand women believed that self-sampling methods could not be a first line screening method due the low effectiveness. Those perceptions could be related with a low familiarization with selfsampling techniques and a lack of knowledge about their high sensitivity when compared with pap smear (36). Education is crucial: with adequate training and information women find self-sampling methods easy and safe to perform. This can increase the willingness to up take those methods (43). Promotional and educational activities led by nurses and midwives in community settings could break down barriers for self-sampling methods and for cervical-cancer screening (44) (45).

Women in our FGD consider that if the self sampling is performed in their household and transported to the health centers, two problems can appear: first, samples could be damaged during transportation and second, samples could arrive too late to the laboratory and become ineffective. Those situations could be solved by ensuring an organized program, that includes transportation of samples and reduces waiting times; this could increase the satisfaction and uptake of self-sampling methods (46).

Self-sampling has demonstrated to be a cost-effective test in different settings. However, further research should address the practical acceptance of women in rural areas. The knowledge about barriers and perceived disadvantages, as documented in our study, could tailor targeted educational modules for participants as well as health care workers in the field.

In the next step of CAMIE project, we will evaluate the acceptance, sensitivity and specificity of vaginal self- sampling, urine sampling, and clinician sampling in rural areas.

A limitation of this study is that in Ecuador self-sampling methods are still not available; despite the fact that we presented the devices in the FDG, interviewed women could only imagine how it would be to perform self-sampling methods.

\section{Conclusions}

The aim of this study was to identify the perceptions of self sampling and urine sampling versus traditional pap smear in rural settings of Cuenca Ecuador. This study was the first one in Ecuador to test the acceptance of those innovative methods. The results demonstrate that the participants consider that self-sampling methods could overcome barriers that reduce the uptake of cervical cancer screening like waiting time, pain, or embarrassment and that they could be a good option for screening in rural areas. Involving health personnel and traditional medicine practitioners could further increase the success of a selfsampling program.

Barriers for implementation of self-sampling methods are related with fears to take a quality sample, to get hurt during the self examination and doubts about accuracy of the results. Those barriers could be overcome with adequate training and information for the patients.

Further studies should be done, testing the acceptance and sensitivity/specificity of self-sampling methods in the field. Those methods are a promising strategy in LMIC, with a low adherence to cervical screening.

\section{Abbreviations}

CC: Cervical cancer

CAMIE: Cáncer Auto Muestreo Igualdad Empoderamiento ) Cancer Self Sampling equity empowerment

Page $11 / 15$ 
DIUC: Dirección de investigación de la Universidad de Cuenca ) direction of research of the university of Cuenca

FGD: Focus groups of discussion

HPV: Human papillomavirus

LMIC: Low and middle income countries

Q: Quotation

SRQR: Standards for reporting qualitative research

UC-COBIAS: University de Cuenca Comité de Bioética de las áreas de la Salud ) University of Cuenca Comitee of Bioathics of Health Science Areas

VLIR-UOS: Vlaamse Interuniversitaire Raad Universitaire Ontwikkelingssamenwerking (Flemish Interuniversities Council University Development Co-operation)

\section{Declarations}

\section{Acknowledgements}

Funding was provided by VLIR-UOS as a part of the project entitled "Making cervix cancer screening accessible through self sampling: a step towards health equality by empowering women in an intercultural context (CAMIE)". We are grateful to all the participants who provided their knowledge. Our sincere thanks go to people who helped us in the focus groups and collaborated in this project: Miguel Castro, Jorge Mejía,

We also thank the institutions that have supported us: University of Antwerp, Universidad Universidad de Cuenca, Dirección de Investigación de la Universidad de Cuenca (DIUC), Universidad Técnica Particular de Loja, Ministry of public health of Ecuador, Primary health centers from El Valle and Gualalcay, Autonomous government of the El Valle parish.

\section{Authors' contributions}

BV was involved in the research conception and design, data collection and analysis, and in the drafting and final revision of the manuscript; JO was involved in the research conception and design; GG was involved in the data collection and analysis. RMR was involved in the research design and critically revised the manuscript for important intellectual content. AN was involved in the research design and critically revised the manuscript; DL was involved in the data collection research conception and design, data collection; IB final revision of the manuscript and critically revised the manuscript for important intellectual content TP revised the manuscript for important intellectual content, VV was involved research conception and design, data analysis, the drafting and final revision of the manuscript and critically revised the manuscript for important intellectual content All authors read and approved the final manuscript .

\section{Conflicts of interest}

The authors declare that they have no financial or personal relationship(s) that may have inappropriately influenced them in conducting the research or writing this article.

\section{Funding}

Funding was obtained from VLIRUOS (Flemish Interuniversity Council for University Development Cooperation) Cuenca University Research Direction (DIUC).

Availability of data and materials The datasets generated and/or analyzed during the current study are not publicly available because the focus groups contain sensitive personal data and the transcripts have the names of participants. The 
informed consent grants the confidentiality of the of the participants' data. However, the datasets are available from the corresponding author on reasonable request.

\section{Ethics approval and consent to participate:}

This study was approved under guidance of the Declaration of Helsinki and the Council for International Organizations of Medical Sciences (CIOMS). All procedures involving human participants were approved by the Bioethical Committee of the University of Cuenca, approval code: UC-COBIAS-2020-263. Before the starting of each FGD, an informed consent was signed by each participant who was free to decline participation or withdraw at any time

Consent for publication: The participants consented to their anonymised data being published at the time of informed consent via the consent form.

\section{References}

1. Buskwofie A, David-West G, Clare CA. A Review of Cervical Cancer: Incidence and Disparities. Journal of the National Medical Association. 2020 Apr;112(2):229-32.

2. Sung H, Ferlay J, Siegel RL, Laversanne M, Soerjomataram I, Jemal A, et al. Global Cancer Statistics 2020: GLOBOCAN Estimates of Incidence and Mortality Worldwide for 36 Cancers in 185 Countries. CA A Cancer J Clin. 2021 May;71(3):20949.

3. Perehudoff K, Vermandere H, Williams A, Bautista-Arredondo S, De Paepe E, Dias S, et al. Universal cervical cancer control through a right to health lens: refocusing national policy and programmes on underserved women. BMC Int Health Hum Rights. 2020 Dec;20(1):21.

4. World Health Organization. Global strategy to accelerate the elimination of cervical cancer as a public health problem [Internet]. World Health Organization; 2020. Available from: https://www.who.int/publications/i/item/9789240014107

5. Ackerson K, Gretebeck K. Factors influencing cancer screening practices of underserved women: Factors influencing cervical cancer screening. Journal of the American Academy of Nurse Practitioners. 2007 Nov;19(11):591-601.

6. Canfell K, Kim JJ, Brisson M, Keane A, Simms KT, Caruana M, et al. Mortality impact of achieving WHO cervical cancer elimination targets: a comparative modelling analysis in 78 low-income and lower-middle-income countries. The Lancet. 2020 Feb;395(10224):591-603.

7. Urrutia M-T, Araya A, Jaque M-F. Why Do Chilean Women Choose to Have or Not Have Pap Tests? Journal of Obstetric, Gynecologic \& Neonatal Nursing. 2017 Jan;46(1):e3-12.

8. Agurto I, Bishop A, Sánchez G, Betancourt Z, Robles S. Perceived barriers and benefits to cervical cancer screening in Latin America. Preventive Medicine. 2004 Jul;39(1):91-8.

9. Zorogastua K, Erwin D, Thelemaque L, Pulley L, Jandorf L. Intrinsic Factors of Non-adherence to Breast and Cervical Cancer Screenings Among Latinas. J Racial and Ethnic Health Disparities. 2016 Dec;3(4):658-66.

10. Nugus P, Désalliers J, Morales J, Graves L, Evans A, Macaulay AC. Localizing Global Medicine: Challenges and Opportunities in Cervical Screening in an Indigenous Community in Ecuador. Qual Health Res. 2018 Apr;28(5):800-12.

11. Galvão JR, Almeida PF de, Santos AM dos, Bousquat A. Percursos e obstáculos na Rede de Atenção à Saúde: trajetórias assistenciais de mulheres em região de saúde do Nordeste brasileiro. Cad Saúde Pública. 2019;35(12):e00004119.

12. International Agency for Research in Cancer. International Agency for Research in Cancer. Ecuador Fact sheets 2020. [Internet]. IARC; 2021. Available from: https://gco.iarc.fr/today/data/factsheets/populations/218-ecuador-fact-sheets.pdf

13. Bruni L, Albero G, Serrano B, Mena M, Gómez D, Muñoz J, Bosch FX, de Sanjosé S. Human Papillomavirus and Related Diseases Report Ecuador [Internet]. ICO/IARC Information Centre on HPV and Cancer (HPV Information Centre); 2019. Available from: https://hpvcentre.net/statistics/reports/ECU.pdf

14. Vega B, Sacoto C. Prevalencia de cáncer de cuello uterino en el Ecuador y estrategias para su reducción [Internet]. Facultad de Ciencias Médicas Universidad de Cuenca; 2012. Available from: 
https://dspace.ucuenca.edu.ec/bitstream/123456789/20387/1/Bernardo\%20Vega\%20C.\%20y\%20Catalina\%20Sacoto.pdf

15. Ministerio de Salud Pública del Ecuador. Estrategia Nacional para la prevención del Cáncer en el Ecuador 2017 [Internet]. MSP; 2017. Available from:

https://aplicaciones.msp.gob.ec/salud/archivosdigitales/documentosDirecciones/dnn/archivos/ac_0059_2017.pdf

16. Ministerio de Salud Pública del Ecuador. Plan Nacional de Salud Sexual y Salud Repoductiva 2017-2021.pdf [Internet]. MSP; 2017. Available from: https://ecuador.unfpa.org/sites/default/files/pub-

pdf/PLAN\%20NACIONAL\%20DE\%20SS\%20Y\%20SR\%202017-2021.pdf

17. Ministerio de Salud Pública del Ecuador M. Esquema de vacunación Ecuador .2019.ok_.pdf [Internet]. 2019. Available from: https://www.salud.gob.ec/wp-content/uploads/2020/01/ESQUEMA-DE-VACUNACIO\%CC\%81N.DIC_.2019.ok_.pdf

18. Ministerio de Salud Pública del Ecuador M. Protocolos con evidencia para la detección oportuna del cáncer de cuello uterino. $2015 ; 13$.

19. Instituto Nacional de Estadísticas y Censos. Encuesta Nacional de Salud y Nutrición 2018 [Internet]. INEC; 2018. Available from: https://www.ecuadorencifras.gob.ec/documentos/webinec/Estadisticas_Sociales/ENSANUT/ENSANUT_2018/Principales\%20resultados\%20ENSANUT_2018.pdf

20. Baezconde-Garbanati L, Agurto I, Gravitt PE, Luciani S, Murphy S, Ochoa C, et al. Barriers and innovative interventions for early detection of cervical cancer. Salud Publica Mex. 2019 Aug 12;61(4, jul-ago):456.

21. Kang M, Ha SY, Cho HY, Chung DH, Kim NR, An J, et al. Comparison of papanicolaou smear and human papillomavirus (HPV) test as cervical screening tools: can we rely on HPV test alone as a screening method? An 11-year retrospective experience at a single institution. J Pathol Transl Med. 2020 Jan 15;54(1):112-8.

22. Ogilvie GS, van Niekerk D, Krajden M, Smith LW, Cook D, Gondara L, et al. Effect of Screening With Primary Cervical HPV Testing vs Cytology Testing on High-grade Cervical Intraepithelial Neoplasia at 48 Months: The HPV FOCAL Randomized Clinical Trial. Obstetrical \& Gynecological Survey. 2018 Nov;73(11):632-4.

23. Madzima TR, Rn MV, Ccfp AL. Emerging role of HPV self-sampling in cervical cancer screening for hard-to-reach women. 2017;5.

24. Nelson EJ, Maynard BR, Loux T, Fatla J, Gordon R, Arnold LD. The acceptability of self-sampled screening for HPV DNA: a systematic review and meta-analysis. Sex Transm Infect. 2017 Feb;93(1):56-61.

25. Lorenzi AT, Fregnani JHT, Dockter J, Fitzgerald K, Strohecker E, Eaton B, et al. High-Risk Human Papillomavirus Detection in Urine Samples From a Referral Population With Cervical Biopsy-Proven High-Grade Lesions: Journal of Lower Genital Tract Disease. 2018 Jan;22(1):17-20.

26. Agorastos T, Chatzistamatiou K, Tsertanidou A, Mouchtaropoulou E, Pasentsis K, Kitsou A, et al. Implementation of HPVbased Cervical Cancer Screening Combined with Self-sampling Using a Midwifery Network Across Rural Greece: The GRECOSELF Study. Cancer Prev Res. 2019 Oct;12(10):701-10.

27. Vorsters A, Van Damme P, Clifford G. Urine testing for HPV: rationale for using first void. BMJ. 2014 Oct 15;349(oct15 3):g6252-g6252.

28. Murchland AR, Gottschlich A, Bevilacqua K, Pineda A, Sandoval-Ramírez BA, Alvarez CS, et al. HPV self-sampling acceptability in rural and indigenous communities in Guatemala: a cross-sectional study. BMJ Open. 2019 Oct;9(10):e029158.

29. Léniz J, Barriga MI, Lagos M, Ibáñez C, Puschel K, Ferreccio C. HPV vaginal self-sampling among women non-adherent to Papanicolaou screening in Chile. Salud pública Méx. 2013 Apr;55(2):162-9.

30. Malone C, Barnabas RV, Buist DSM, Tiro JA, Winer RL. Cost-effectiveness studies of HPV self-sampling: A systematic review. Preventive Medicine. 2020 Mar;132:105953.

31. Surriabre P, Allende G, Prado M, Cáceres L, Bellot D, Torrico A, et al. Self-sampling for human papillomavirus DNA detection: a preliminary study of compliance and feasibility in BOLIVIA. BMC Women's Health. 2017 Dec;17(1):135.

32. Sekhon M, Cartwright M, Francis JJ. Acceptability of healthcare interventions: an overview of reviews and development of a theoretical framework. BMC Health Serv Res. 2017 Dec;17(1):88.

Page $14 / 15$ 
33. Yeo C, Fang H, Thilagamangai, Koh SSL, Shorey S. Factors affecting Pap smear uptake in a maternity hospital: A descriptive cross-sectional study. J Adv Nurs. 2018 Nov;74(11):2533-43.

34. Grigore M, Popovici R, Pristavu A, Grigore AM, Matei M, Gafitanu D. Perception and use of Pap smear screening among rural and urban women in Romania. European Journal of Public Health. 2017 Dec 1;27(6):1084-8.

35. Kabalika, MBChB C, Mulenga, MPH D, Mazaba, MSc ML, Siziya, PhD S. Acceptance of Cervical Cancer Screening and its Correlates Among Women of a Peri-Urban High-Density Residential Area in Ndola, Zambia. Int J MCH AIDS. 2018 Jul 20;7(1):17-27.

36. Yeh PT, Kennedy CE, de Vuyst H, Narasimhan M. Self-sampling for human papillomavirus (HPV) testing: a systematic review and meta-analysis. BMJ Glob Health. 2019 May;4(3):e001351.

37. Skroumpelos A, Agorastos T, Constantinidis T, Chatzistamatiou K, Kyriopoulos J. Economic evaluation of HPV DNA test as primary screening method for cervical cancer: A health policy discussion in Greece. Lhachimi SK, editor. PLoS ONE. 2019 Dec 12;14(12):e0226335.

38. Bhatla N, Singhal S. Primary HPV screening for cervical cancer. Best Practice \& Research Clinical Obstetrics \& Gynaecology. 2020 May;65:98-108.

39. Shin HY, Lee B, Hwang S-H, Lee DO, Sung NY, Park JY, et al. Evaluation of satisfaction with three different cervical cancer screening modalities: clinician-collected Pap test vs. HPV test by self-sampling vs. HPV test by urine sampling. J Gynecol Oncol. 2019;30(5):e76.

40. Rosenbaum AJ, Gage JC, Alfaro KM, Ditzian LR, Maza M, Scarinci IC, et al. Acceptability of self-collected versus providercollected sampling for HPV DNA testing among women in rural El Salvador. International Journal of Gynecology \& Obstetrics. 2014 Aug;126(2):156-60.

41. Dutton T, Marjoram J, Burgess S, Montgomery L, Vail A, Callan N, et al. Uptake and acceptability of human papillomavirus self-sampling in rural and remote aboriginal communities: evaluation of a nurse-led community engagement model. BMC Health Serv Res. 2020 Dec;20(1):398.

42. Sy AU, Hernandez BY, Tareg A, Reichhardt M, Buenconsejo-Lum L. Acceptability and feasibility of a community based participatory research project comparing cytology and urine HPV DNA testing for cervical cancer screening in Yap, Federated States of Micronesia. Cancer Epidemiology. 2017 Oct;50:283-8.

43. Ørnskov D, Jochumsen K, Steiner PH, Grunnet IM, Lykkebo AW, Waldstrøm M. Clinical performance and acceptability of self-collected vaginal and urine samples compared with clinician-taken cervical samples for HPV testing among women referred for colposcopy. A cross-sectional study. BMJ Open. 2021 Mar;11(3):e041512.

44. Ruddies F, Gizaw M, Teka B, Thies S, Wienke A, Kaufmann AM, et al. Cervical cancer screening in rural Ethiopia: a crosssectional knowledge, attitude and practice study. BMC Cancer. 2020 Dec;20(1):563.

45. Saei Ghare Naz M, Kariman N, Ebadi A, Ozgoli G, Ghasemi V, Rashidi Fakari F. Educational Interventions for Cervical Cancer Screening Behavior of Women: A Systematic Review. Asian Pac J Cancer Prev [Internet]. 2018 Apr [cited 2021 Jul 22];19(4). Available from: https://doi.org/10.22034/APJCP.2018.19.4.875

46. Austad K, Chary A, Xocop SM, Messmer S, King N, Carlson L, et al. Barriers to Cervical Cancer Screening and the Cervical Cancer Care Continuum in Rural Guatemala: A Mixed-Method Analysis. JGO. 2018 Dec;(4):1-10. 